\title{
Active and passive microwave signatures of Antarctic firn by means of field measurements and satellite data
}

\author{
Helmut Rott, Klaus Sturm \\ Institut für Meteorologie und Geophysik, Universität Innsbruck, Innrain 52, A-6020 Innsbruck, Austria \\ HeINZ MiLleR \\ Alfred-Wegener-Institut für Polar-und Meeresforschung, D-2850 Bremerhaven, Germany
}

\begin{abstract}
The angular dependence and polarization behaviour of backscattering and emission of polar firn at $5.2 \mathrm{GHz}$ and $10.3 \mathrm{GHz}$ were measured during an oversnow traverse in Dronning Maud Land, Antarctica. The signatures emphasize the importance of snow stratification in the interpretation of microwave remote sensing measurements. Highest backscattering coefficients and little angular variations were observed for refrozen firn near the coast. In permanently dry snow, areas with high accumulation rates and homogeneous snow morphology showed low backscattering coefficients and high emissivities. Pronounced layering and related density variations in low accumulation zones resulted in increased polarization differences of brightness temperatures and increased like-polarized backscattering coefficients. This behaviour is confirmed by the analysis of C-band scatterometer measurements of the Active Microwave Instrument aboard the European Space Agency's ERS-1.
\end{abstract}

\section{INTRODUCTION}

Spaceborne microwave sensors provide valuable data on physical characteristics of surface and upper snow layers of the ice sheets. Significant regional variations of the emission and backscattering properties have been observed over Antarctica and Greenland (Swift and others, 1985; Rott, 1989; Zhang and others, 1989; Fily and Benoist, 1991). Explanations of microwave signatures over the permanently dry snow areas include variations of snow morphology related to accumulation rate and temperature (Zwally, 1977; Rotman and others, 1982), surface roughness properties (Remy and Minster, 1991), sub-surface layering (Gurvich and others, 1973), as well as combinations of surface roughness and volume scattering (Ridley and Partington, 1988). Currently available theoretical models on the interaction of microwaves with dry snow assume spherical or spheroidal ice grains as scatterers (Fung and Chen, 1989; Tsang and Ding, 1991), but do not take into account the large number of internal boundaries observed in polar firn.

To provide a data base for the analysis of spaceborne microwave measurements, field studies of microwave signatures of snow and ice were initiated by the German Alfred-Wegener-Institut in cooperation with other institutions. During the first of these field campaigns, carried out in summer 1989-90 in Dronning Maud Land, Antarctica, we performed signature measurements in the $\mathrm{X}$ - and C-bands. Further information on the angular dependence of backscattering in the C-band was derived from scatterometer measurements of the European Remote Sensing Satellite ERS-1.

\section{FIELD MEASUREMENTS}

During an oversnow traverse from the German coastal station Georg-von-Neumayer $(\mathrm{GvN})$ to a traverse across Heimefrontfjella mountains between 28 December 1989 and 28 February 1990, we measured backscattering and emission properties of snow in the C- and X-bands (Fig. 1). Measurement sites were at GvN and along a profile of $200 \mathrm{~km}$ length across the Heimfrontfjella from Veststraumen (V) to Base Camp (B) and Amundsen Ice (AI) at elevations between $500 \mathrm{~m}$ and $2300 \mathrm{~m}$ a.s.l.

\section{Firn properties}

In the area of the field campaign temporary summer melt is observed at elevations below $500 \mathrm{~m}$ a.s.l. up to $150 \mathrm{~km}$ inland from the coast. Near GvN the stratigraphic profile of the top $4 \mathrm{~m}$ of the snowpack typically shows two to three ice layers per $\mathrm{m}$ with thicknesses between $5 \mathrm{~mm}$ and $20 \mathrm{~mm}$, as well as two depth hoar layers per m. Microwave measurements at GvN were made at the end of February, when the snowpack was completely frozen.

Along the Heimefrontfjella profile no indications of summer melt were observed. Nevertheless, the morph- 

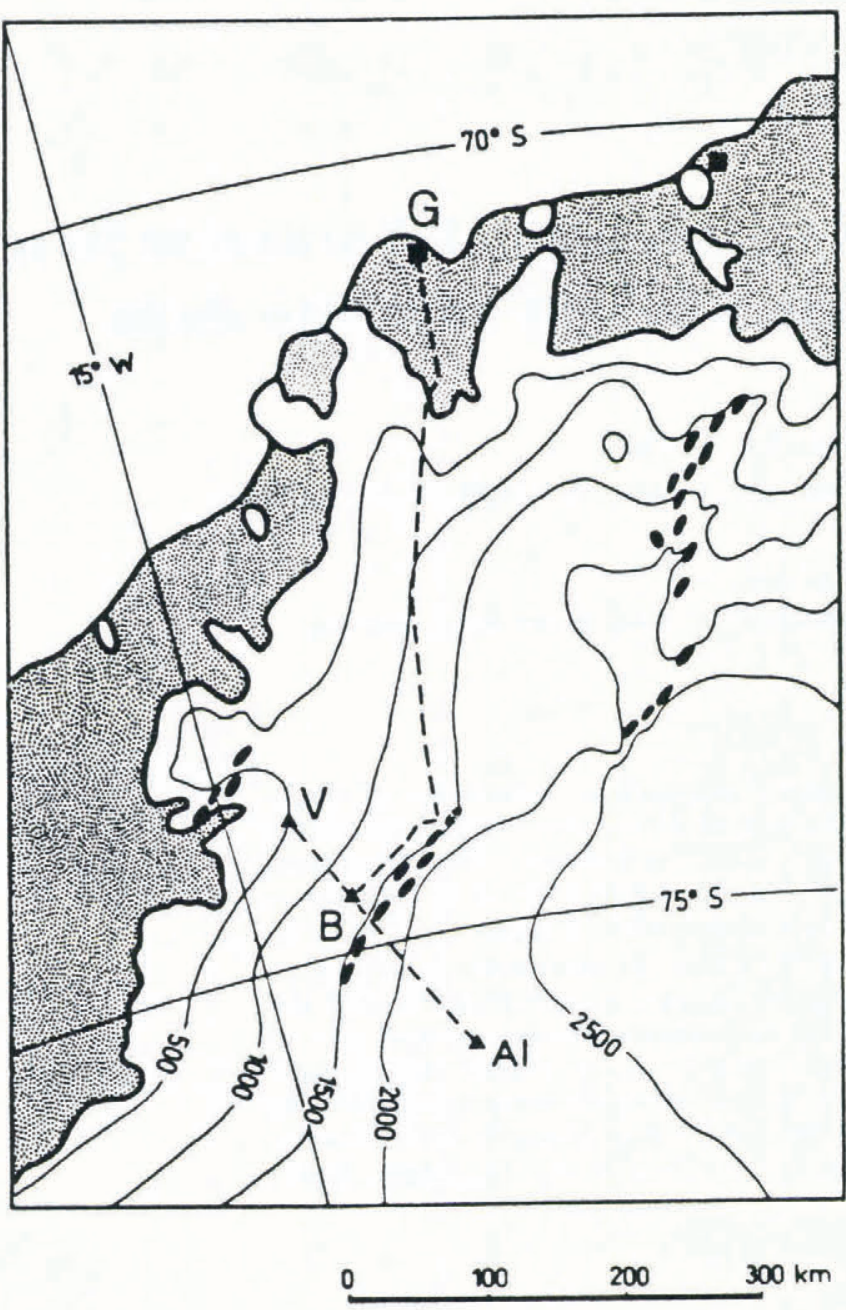

Fig. 1. Location map of the oversnow traverse 1989/90 of the Alfred-Wegener-Institut. Ice shelves are shaded. Measurement sites: G: Georg-von-Neumayer station, $V$ : Veststraumen, B: Base Camp, AI: Amundsen Ice.

ology of the snowpack across the profile was quite variable, caused primarily by differences in accumulation rate and mean temperature. Table 1 summarizes snow characteristics at three sites located in the northern, central, and southern part of the profile, respectively. The highest annual accumulation rate and highest mean snow density was observed at site $\mathrm{B}$, which was located at an elevation of $1200 \mathrm{~m}, 20 \mathrm{~km}$ northwest of the main ridge of the Heimefrontfjella, the highest peaks of which rise to
$2700 \mathrm{~m}$. Increased snowfall due to orographic effects and deposition of drift snow by katabatic winds downstream from the mountain slopes are the reasons for the comparatively high accumulation rate of $350 \mathrm{~kg} \mathrm{~m}^{-2} \mathrm{a}^{-1}$.

Density profiles (Fig. 2) reflect the differences in the accumulation regime. The density measurements were made for layers of $5 \mathrm{~cm}$ thickness, which is not adequate to resolve densities of thin layers. At site B horizontal layering was less pronounced than at the two other sites, and grain sizes were more homogeneous. At site AI strong density variations were related to depth-hoar layers, which are formed in late summer and autumn below thin wind-crusts. Here in each of two snow pits eight distinct depth hoar layers were found within the top $2 \mathrm{~m}$, with very loose snow and hexagonal plates of up to $4 \mathrm{~mm}$ diameter. During the field campaign, wind velocities were in general low, and surfaces at all measurement sites were remarkably smooth.

\section{Microwave penetration}

For the interpretation of microwave signatures, knowledge on the depth of the snow volume contributing to emission and backscattering is essential. Penetration of microwaves in snow is limited by losses due to scattering at inhomogeneities and absorption. Typically, at frequencies below $10 \mathrm{GHz}$, scattering losses are neglected, and the penetration depth is calculated by means of the effective dielectric constant $\epsilon$, which is derived from volumetrically weighted averages of the dielectric constants of the constituents (air and ice in case of dry snow) by means of mixing models (Stiles and Ulaby, 1982).

According to equations given by Mätzler (1987), we calculate the real part $\epsilon^{\prime}$ and the imaginary part $\epsilon^{\prime \prime}$ of the dielectric constant of dry snow at $-15^{\circ} \mathrm{C}$ with a density of $440 \mathrm{~kg} \mathrm{~m}^{-3}: \epsilon^{\prime}=1.87 ; \epsilon^{\prime \prime}(5.2 \mathrm{GHz})=1.0 \times 10^{-4} ; \epsilon^{\prime \prime}$ $(10.3 \mathrm{GHz})=2.1 \times 10^{-4}$. The absorption coefficient $k_{\mathrm{a}}$ derived by

$$
k_{\mathrm{a}}=\left(2 \pi \epsilon^{\prime \prime}\right) /\left(\lambda_{0} \sqrt{ } \epsilon^{\prime}\right)
$$

amounts to $k_{\mathrm{a}}=0.008$ for $5.2 \mathrm{GHz}$ and $k_{\mathrm{a}}=0.0332$ for $10.3 \mathrm{GHz}$ for the snow conditions specified above.

In stratified polar firn, losses due to specular and diffuse reflection at internal boundaries between layers with different densities, as well as volume scattering at ice grains, have to be considered. Taking into account the dimension of the inhomogeneities in relation to wave-

Table 1. Snow characteristics at measurement sites

Height a.s.l.

Accumulation rate Density (0-2 m)

$10 \mathrm{~m}$ firn temperature

$\mathrm{m}$

$$
\mathrm{kg} \mathrm{m}^{-2} \mathrm{a}^{-1} \quad \mathrm{~kg} \mathrm{~m}^{-3}
$$

\section{Vestraumen}

Base Camp

Amundsen Ice

$74^{\circ} 20^{\prime} \mathrm{S}$
$74^{\circ} 45^{\prime} \mathrm{S}$
$75^{\circ} 33^{\prime} \mathrm{S}$

$13^{\circ} 45^{\prime} \mathrm{W}$

$12^{\circ} 24^{\prime} \mathrm{W}$

$10^{\circ} 17^{\prime} \mathrm{W}$

500
1200
2250

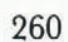

350

130
$-33$ 
Rott and others: Microwave signatures of Antarctic firn

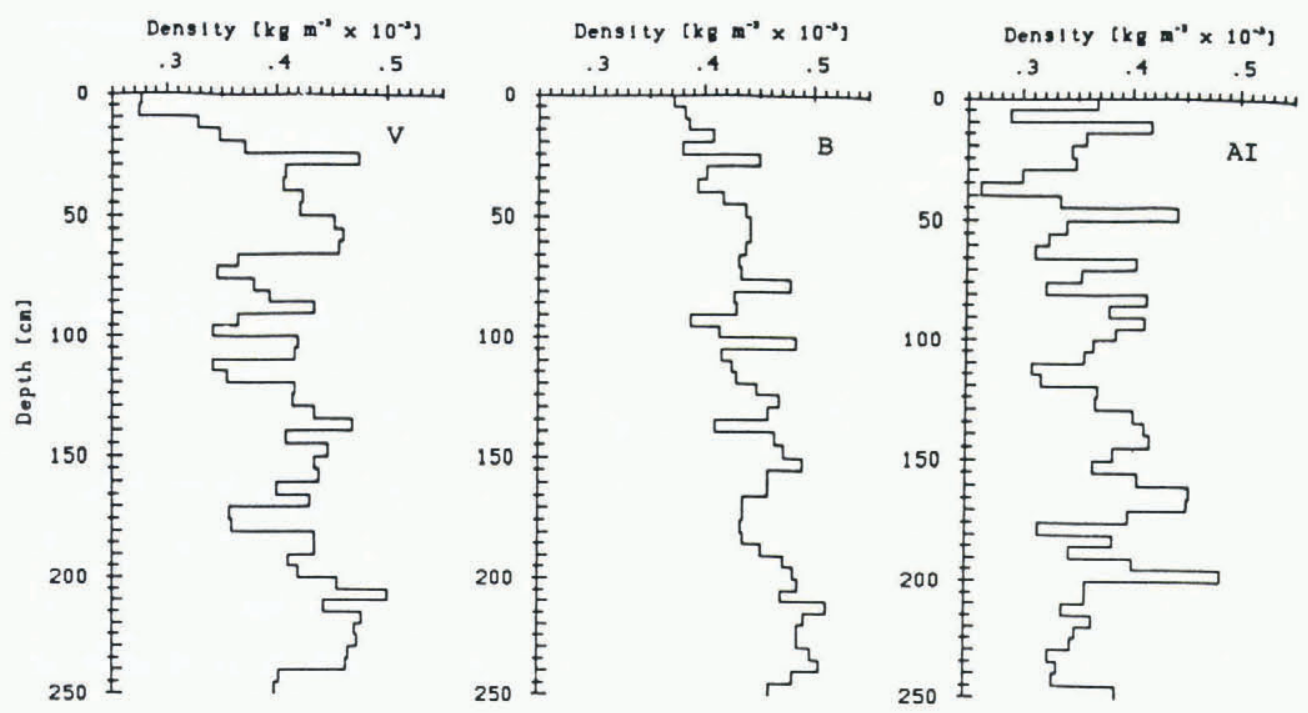

Fig. 2. Snow density as function of depth at three sites V: Veststraumen, B: Base Camp, AI: Amundsen Ice.

length, at frequencies $\leq 10 \mathrm{GHz}$ scattering losses at the grains should be significantly smaller than absorption losses. However, reflections at internal boundaries of polar firn show up very clearly in X-band radar measurements (Forster and others, 1991). Because the volume inhomogeneities of polar firn, from grains to layers, cover two orders of magnitude and show considerable regional variations, calculations on propagation of microwaves in the medium is a difficult task. Our estimates of penetration depth of dry polar firn are based on field measurements of transmissivity and on satellite radiometer measurements.

Figure 3 shows vertical profiles of the extinction coefficient $k_{\mathrm{e}}$ at $5.2 \mathrm{GHz}$ and $10.3 \mathrm{GHz}$, derived by means of radiometric transmission measurements on snow blocks of $0.3 \mathrm{~m}$ thickness, which were cut out of a snow pit at Base Camp. Transmittance $t_{\mathrm{s}}$ of the radiation flux through a snow block was determined according to

$$
t_{\mathrm{s}}=\left(T_{\mathrm{s}}-T_{\mathrm{m}}\right) /\left(T_{\mathrm{s}}-T_{\mathrm{sky}}\right),
$$

where $T_{\mathrm{s}}$ is the thermodynamic temperature of the snow, $T_{\mathrm{m}}$ is the brightness temperature measured by the radiometer looking toward the sky with the snow block

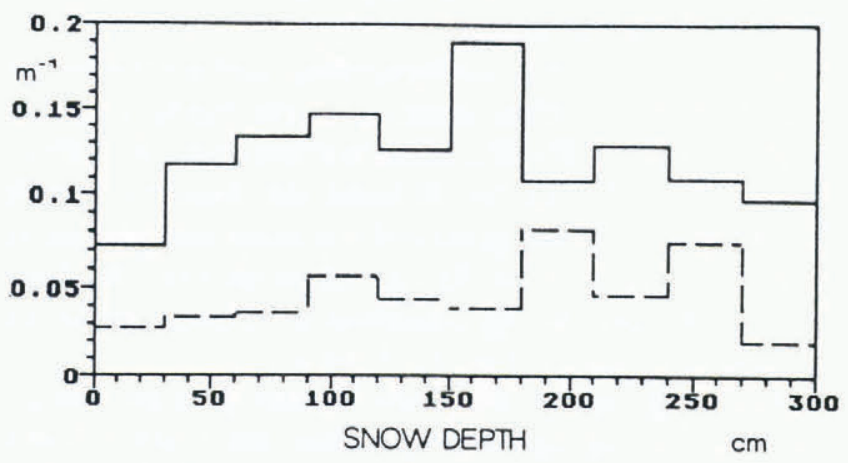

Fig. 3. Extinction coefficient $k_{\mathrm{e}}\left(\mathrm{m}^{-1}\right)$ of the top $3 \mathrm{~m}$ of firn at Base Camp, determined by means of transmission measurements at $5.2 \mathrm{GHz}$ (broken line) and $10.3 \mathrm{GHz}$ (full line). in front of the antenna, and $T_{\text {sky }}$ is the brightness temperature of the sky.

The extinction coefficient $k_{\mathrm{e}}$, which includes scattering and absorption losses, is related to transmittance by

$$
t_{\mathrm{s}}=\exp \left(-k_{\mathrm{e}} \delta z\right)
$$

with $\delta z=0.3 \mathrm{~m}$. Mean $k_{\mathrm{e}}$ values for the top $3 \mathrm{~m}$ of the snow pit were:

$$
\begin{aligned}
& k_{\mathrm{e}}=0.046 \mathrm{~m}^{-1} \text { at } 5.2 \mathrm{GHz}, \\
& k_{\mathrm{e}}=0.123 \mathrm{~m}^{-1} \text { at } 10.3 \mathrm{GHz} .
\end{aligned}
$$

These values are close to those reported by Mätzler (1987) for dry alpine snow, and are also in agreement with $k_{\mathrm{e}}$ values which we derived by inversion calculations from Nimbus-7 Scanning Multichannel Microwave Radiometer (SMMR) measurements (Rott, 1989). With $\left(\mathrm{d}_{\mathrm{p}}=1 / k_{\mathrm{e}}\right)$ we obtain the penetration depths shown in Table 2. The SMMR-based $d_{p}$ values were derived by numerical calculations of radiative transfer, based on the comparison of annual amplitudes of snow temperatures down to $10 \mathrm{~m}$ depth with annual amplitudes of SMMR brightness temperatures (Rott, 1989).

Table 2. Penetration depth $d_{p}$ of polar firn at various frequencies $f$ derived (I) by means of field measurements at the Base Camp; (II) by inversion calculations of annual brightness temperature amplitudes measured by SMMR in

\begin{tabular}{|c|c|c|c|c|c|c|c|}
\hline$f$ & (GHz) & 5.2 & 10.3 & 6.6 & 10.7 & 18.0 & 37.0 \\
\hline$d_{p}$ & (m) & 21.7 & 8.1 & 17.8 & 10.4 & 3.2 & 0.85 \\
\hline
\end{tabular}
the areas of the East Antarctic stations, Plateau and Mizuho (Rott, 1989)
II 

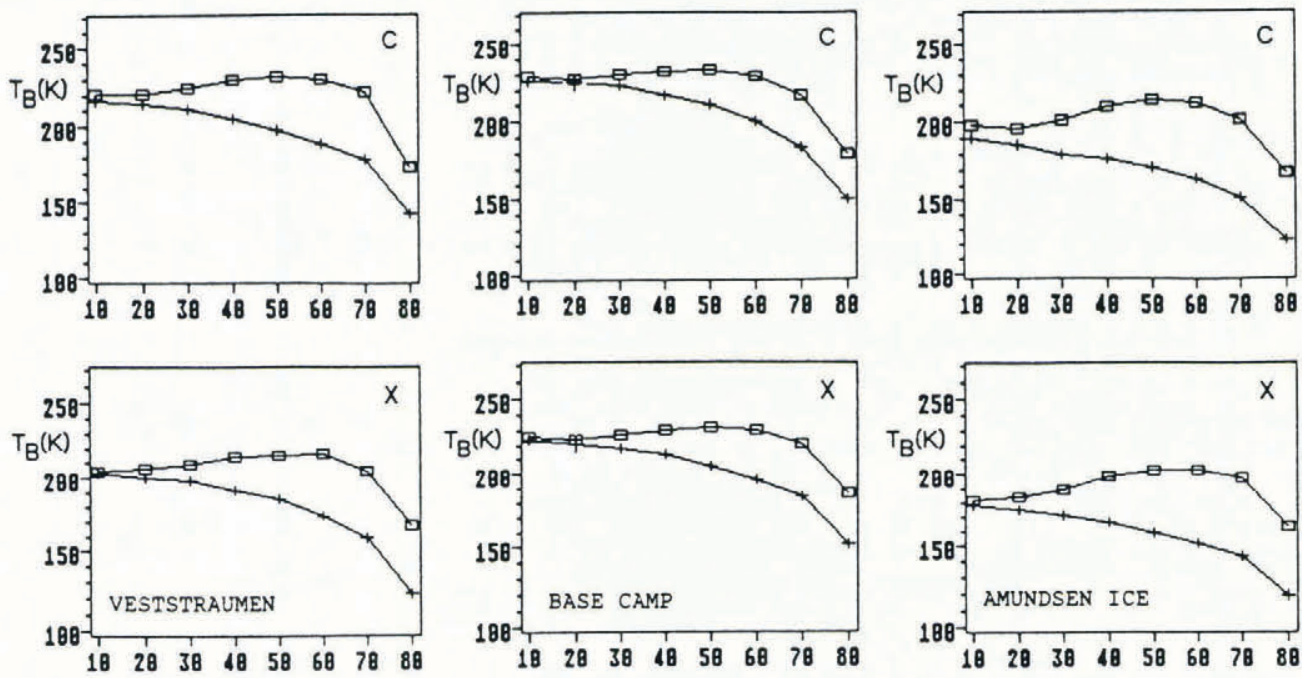

Fig. 4. $C$ - and $X$-band brightness temperatures $\mathcal{T}_{\mathrm{b}}$ at vertical polarization $(\square)$ and horizontal polarization $(+)$ versus incidence angle, measured at Veststraumen, Base Camp and Amundsen Ice.

\section{C- and $X$-band emission and backscattering measurements}

Measurements were carried out with a dual frequency scatterometer/radiometer, which was mounted $3.5 \mathrm{~m}$ above the surface on the sidewall of a container for measurements at incidence angles between $10^{\circ}$ and $80^{\circ}$, and on the crane of a snow-mobile for nadir measurements. The two radiometers are of the unbalanced Dicke type with center frequencies respectively of $5.25 \mathrm{GHz}$, bandwidth $0.56 \mathrm{GHz}$, and $10.3 \mathrm{GHz}$, bandwidth $1.06 \mathrm{GHz}$. The scatterometer operates with a separate noise transmitter in each channel and uses the radiometers as receivers. Two turnable horn antennae per channel, with half-power beamwidths of $18^{\circ}$ enable measurements at different linear polarizations. Advantages of the noise system are the large number of independent samples and the possibility of using the same receiver for active and passive measurements. A disadvantage is the lack of range information.

The polarization behaviours of brightness temperatures $T_{\mathrm{b}}$ in Figure 4 clearly reflect the differences in snow stratification at sites $\mathrm{V}, \mathrm{B}$ and $\mathrm{AI}$. At $60^{\circ}$ incidence angle the $T_{\mathrm{b}}$ differences $\left(\delta T_{\mathrm{b}}\right)$ between vertical and horizontal polarization increase from $\mathrm{B}\left(\delta T_{\mathrm{b}}=28 \mathrm{~K}\right.$ in the C-band, $\delta T_{\mathrm{b}}=34 \mathrm{~K}$ in the X-band) to site $\mathrm{V}(41 \mathrm{~K}$ in both bands), and to AI ( $48 \mathrm{~K}$ in the C-band, $50 \mathrm{~K}$ in the Xband). Mean emissivity decreases from $\mathrm{B}$ to $\mathrm{V}$ and to $\mathrm{AI}$. Emissivities are in general slightly lower in the X-band than in the C-band, indicating increased effects of reflections and scattering at the higher frequency.

The behaviour of the active signatures is complementary to the emissivities. Because we could not separate the backscattering contributions of individual layers, we calculated the backscattering coefficient $\gamma$ for given frequency and polarization from the measurements of the reflected power according to

$$
\gamma=P_{\mathrm{r}} / P_{\mathrm{t}}\left(4 \pi R_{\mathrm{eff}} / \lambda\right)^{2}\left(1 / G_{\mathrm{s}}\right),
$$

where $P_{\mathrm{r}}$ is the received power, $P_{\mathrm{t}}$ is the transmitted power, and $G_{\mathrm{s}}$ is the effective scatterometer gain:

$$
G_{\mathrm{s}}=(1 / 4 \pi) \iint g_{\mathrm{r}}(\Theta, \Phi), g_{\mathrm{t}}(\Theta, \Phi) \mathrm{d} \Omega
$$

In our system the gains $g_{\mathrm{r}}$ and $g_{\mathrm{t}}$ of the receiving and transmitting antennae are identical in each channel. The $3 \mathrm{~dB}$ beamwidth for the power measurements, given by the convolution of $g_{\mathrm{r}}$ and $g_{\mathrm{t}}$, is $7-8^{\circ}$, and shows a slight dependence on the range due to the parallax resulting from the spacing between the two antennae. For calculating $\gamma$ of the volume scattering medium, we introduced an effective range:

$$
R_{\text {eff }}=R_{0}+\delta R
$$

where $R_{0}$ is the range from the scatterometer to the snow surface and $\delta R$ is the weighted distance for the backscatter contribution of the snow volume measured from the surface (Rott and Sturm, 1991). By means of radiative transfer calculations we determined values of $\delta R$ $=3 \mathrm{~m}$ for $5.2 \mathrm{GHz}$ and $\delta R=1.5 \mathrm{~m}$ for $10.3 \mathrm{GHz}$. The backscattering coefficient $\gamma$ is normalized to the solid angle and is related to $\sigma^{\circ}$, the radar cross section per unit area, by

$$
\sigma^{\circ}=\gamma \cos \Theta,
$$

where $\Theta$ is the incidence angle of the radar beam measured from the vertical.

The like-polarized backscattering coefficients at all three sites show a clear decrease in the incidence angle range from $10^{\circ}$ to $40-50^{\circ}$, which is of the order of $15 \mathrm{~dB}$ at C-band (Fig. 5). In the X-band the incidence angle dependence of the like-polarized $\gamma$ is more pronounced at sites B and V than at AI. At all three sites the likepolarized backscattering intensities at C-band are lower by a few $\mathrm{dB}$ compared to the $\mathrm{X}$-band.

At site $\mathrm{B}$, where the snow density is more homogeneous, the like-polarized $\gamma$ values are slightly lower than at the two other sites. The $\gamma$ values at $\mathrm{HH}$ and VV polarizations are in close agreement, with the exception of high incidence angles. The differences between copolarized and cross-polarized $\gamma$ are larger in the C-band than the X-band. This can be explained by increasing 

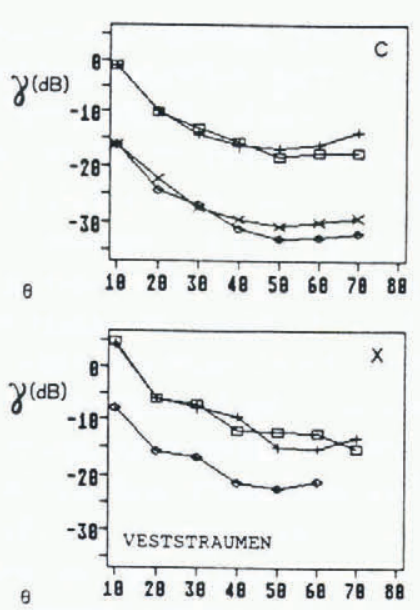
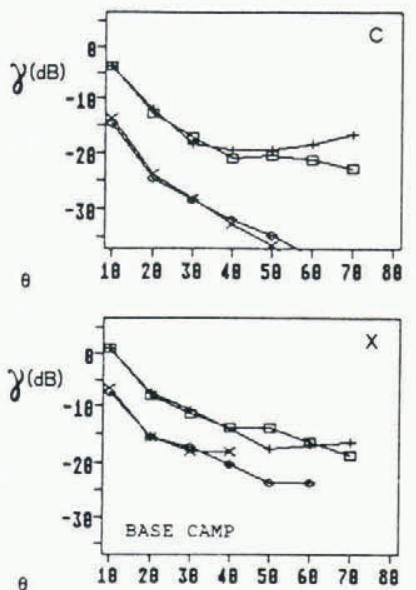
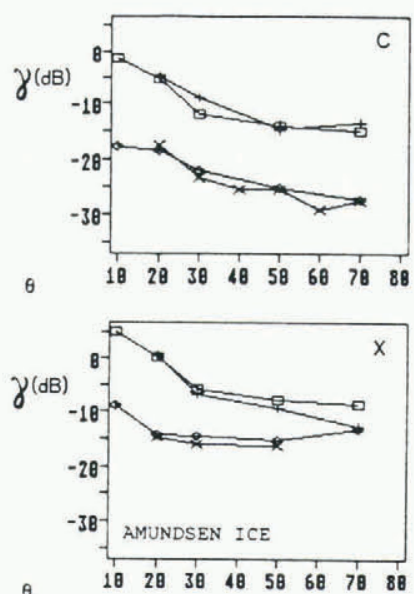

Fig. 5. $C$ - and $X$-band backscatterinng coefficients at the polarizations $V V(\square), H H(+), V H(x), H V(\diamond)$ versus incidence angle, measured at sites Veststraumen, Base Camp and Amundsen Ice.

scattering efficiency of the rough internal interfaces and snow grains with increasing frequency.

\section{Active and passive signatures of refrozen firn}

In Figure 6 results of $T_{\mathrm{b}}$ and $\gamma$ measurements near GvN are plotted. The backscattering coefficients show little dependence on the incidence angle and are - with exception of near nadir incidence - clearly higher than at the other measurement sites, which were located over permanently dry snow areas. Polarization differences of $T_{\mathrm{b}}$ at $\mathrm{GvN}$ are comparable to those at $\mathrm{B}$, but the emissivities $\left(\mathrm{e}=T_{\mathrm{b}} / T\right)$ are clearly lower at GvN, where the mean thermodynamic snow temperature $T$ is about $10^{\circ} \mathrm{C}$ higher. Backscattering and emission signatures at $\mathrm{GvN}$ are typical for a diffusely scattering medium. Ice lenses and ice trunks are strong scatterers at X- and Cband wavelengths.

Georg-von-Neumayer 28. Feb. 90
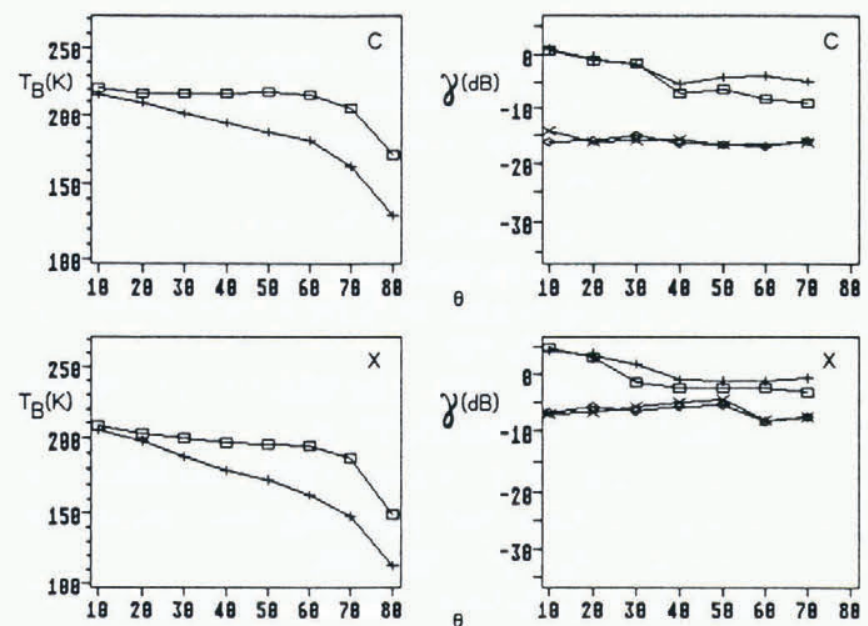

Fig. 6. Brightness temperatures and backscattering coefficients at $C$ - and $X$-band versus incidence angle at Georg-von-Neumayer station, 28 February 1990. Symbols as in Figures 4 and 5.

\section{BACKSGATTERING SIGNATURES MEASURED BY THE ERS-1 SCATTEROMETER}

Our first analysis of $\sigma^{\circ}$, measured by the scatterometer aboard the European Remote Sensing Satellite ERS-1, was based on the period 25-30 November 1991. The Active Microwave Instrument (AMI) of ERS-1 operates at $5.3 \mathrm{GHz}, \mathrm{VV}$ polarizations. In scatterometer mode, AMI measures the backscattered intensity across a swath of $500 \mathrm{~km}$ width in three beams, perpendicular to the subsatellite track (mid-beam), and at azimuth angles $\pm 45^{\circ}$ from the mid-beam (fore-beam and aft-beam respectively). The spatial resolution of a scatterometer cell is $50 \mathrm{~km}$, the grid spacing of the processed data is $25 \mathrm{~km}$ (Francis and others, 1991).

Figure 7 shows examples of the angular dependence of $\sigma^{\circ}$ for four areas with different firn properties: an area covering $100 \times 100 \mathrm{~km}^{2}$ around the site AI, an area of $200 \times 200 \mathrm{~km}^{2}$ around Dome C $\left(74.5^{\circ} \mathrm{S}, 132.2^{\circ} \mathrm{E}\right.$, $3240 \mathrm{~m}$ a.s.l.), an area of $200 \times 200 \mathrm{~km}^{2}$ around Siple Station $\left(75.9^{\circ} \mathrm{S}, 84.2^{\circ} \mathrm{W}, 1050 \mathrm{~m}\right)$, and an area of $50 \times 50 \mathrm{~km}^{2}$ size on the Ekströmisen south of GvN.

Because the limited data set did not allow for detailed analysis of the azimuth dependence of $\sigma^{\circ}$, we averaged over all azimuth angles for each of the beams. Preliminary analysis indicates some variations of $\sigma^{\circ}$ with the azimuth angle within an overall range of less than $3 \mathrm{~dB}$ at each of the four sites shown. At other areas in Antarctica, in particular in regions with strong katabatic winds, we found more pronounced azimuth dependence of $\sigma^{\circ}$.

Scattering of the $\sigma^{\circ}$ data, plotted in steps of $2^{\circ}$ in Figure 7, at AI and Ekström Ice Shelf, can be explained by the small data set and the spatial variability of snow morphology due to orographic effects in these areas. Considering these limitations and the differences in the footprint sizes, the correspondence of $\sigma^{\circ}$ measured by ERS-1 AMI over AI and Ekström with the field measurements at $\mathrm{AI}$ and $\mathrm{GvN}$, respectively, is satisfactory. At the other field measurement sites the inhomogeneities at the AMI footprint scale, due to crevasse zones and mountains, were too big to allow the comparison.

In correspondence with the ground-based scatterometer measurements at GvN, $\sigma^{\circ}$ measured by AMI at 

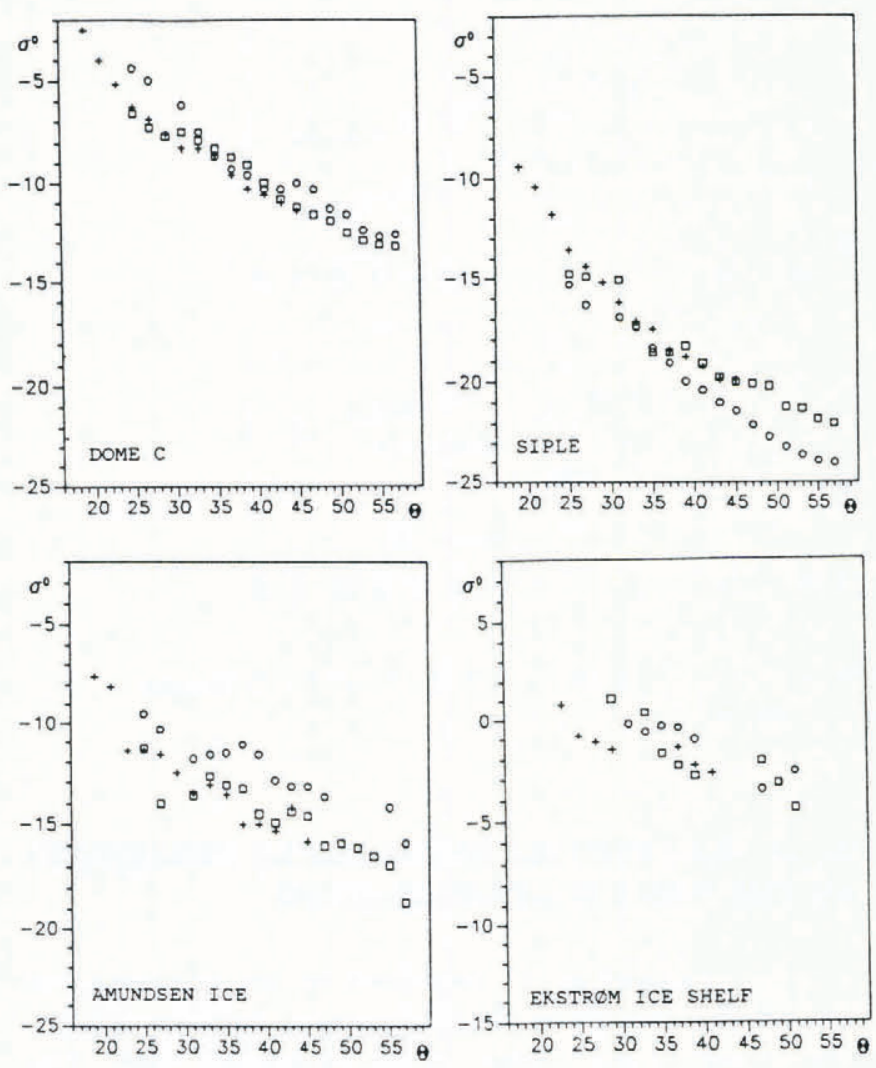

Fig. 7. Radar cross section $\sigma^{\circ}$ in $d B$ versus incidence angle from ERS-1 scatterometer measurements on 25-30 November 1991, at Dome C, Siple, Amundsen Ice and Ekströmisen. $\bigcirc$ : fore-beam, +: mid-beam, $\square:$ aftbeam. Scale for Ekströmisen is shifted by $10 \mathrm{~dB}$.

the Ekström Ice Shelf is clearly higher and shows less variation with the incidence angle than at the other sites. The strongest decrease of $\sigma^{\circ}$ with the incidence angle and the lowest $\sigma^{\circ}$ values are observed at Siple. At incidence angles below $30^{\circ}$ the $\sigma^{\circ}$ values at Siple are $10 \mathrm{~dB}$ below those at Dome C. The backscattering properties for these two sites, which are both in regions of permanently dry snow, reflect the differences in firn stratigraphy. At Siple the accumulation rate is $560 \mathrm{~kg} \mathrm{~m}^{-2} \mathrm{a}^{-1}$, mean annual temperature is $-24^{\circ} \mathrm{C}$ (Mosley-Thompson and others, 1991 ), versus $34 \mathrm{~kg} \mathrm{~m}^{-2} \mathrm{a}^{-1}$ and $-53^{\circ} \mathrm{C}$ at Dome $\mathrm{C}$ (Palais and others, 1982). Snow pit studies at Dome C showed horizontally discontinuous strata and close sequences of thin layers with significant differences in density. The variations of small-scale surface topography at Dome C are typically of the order of $10-20 \mathrm{~cm}$ over distances of several meters, which can be considered to be a rather smooth surface in the C-band. The surface properties, the angular dependence of $\sigma^{\circ}$, as well as the penetration depth of cold firn, clearly point out that the differences between Siple and Dome C are primarily due to the backscattering contribution of the volume. Surface effects can play only a minor role with exception of backscattering near nadir.

\section{CONGLUSION}

In permanently dry firn, areas with high accumulation rate and comparatively homogeneous snow morphology show low backscattering coefficients and high emissivities in the C- and X-bands. Pronounced stratification, including depth hoar layers, results in increased backscattering intensities and in increased brightness temperature differences between horizontal and vertical polarization. Refrozen firn with sub-surface ice layers and ice lenses shows the highest backscattering coefficients with the exception of near-nadir incidence, and only weak angular dependence of backscattering.

The backscattering and emission signatures derived by means of field measurements and satellite data at the various sites with permanently dry firn are clearly different from the behaviour of an ideally diffusely scattering medium. The strong angular dependence of backscattering and the polarization differences of the emitted radiation emphasize the importance of diffuse and specular reflections at internal boundaries. Interfaces between the snow layers retain in many cases the sastrugi structure of the surface, with different roughness scales, from small-scale ripples in $\mathrm{mm}$ to $\mathrm{cm}$ scales to slightly inclined facets of $\mathrm{cm}$ to tens of $\mathrm{cm}$ size. Theoretical models of microwave interaction with polar firn have to take into account the complex structure. Field experiments on microwave signatures, in combination with studies of snow properties, provide an important basis for the analysis of spaceborne microwave measurements over the ice sheets.

\section{ACKNOWLEDGEMENTS}

This work was supported by the Austrian Science Fund (FWF) Project P8476. The Antarctic field campaign $1989 / 90$ was organized and supported by the AlfredWegener-Institut for Polar and Marine Research. The European Space Agency made available the ERS-1 Scatterometer data for AO project Nr. A2.

\section{REFERENGES}

Fily, M. and J.-P. Benoist. 1991. Large-scale statistical study of Scanning Multichannel Microwave Radiometer (SMMR) data over Antarctica. J. Glaciol., 37(125), 129-139.

Forster, R. R., C.H. Davis, T.W. Rand and R. K. Moore. 1991. Snow-stratification investigation on an Antarctic ice stream with an X-band radar system. $\mathcal{F}$. Glaciol., 37(127), 323-325.

Francis, R. and 12 others. 1991. The ERS-1 spacecraft and its payload. ESA Bulletin 65, 27-48.

Fung, A.K. and M.F. Chen. 1989. Modelling of microwave emission and scattering from snow and soil. Adv. Space Res., 9(1), 297-306.

Gurvich, A. S., V. I. Kalinin and D. T. Matveyev. 1973. Influence of the internal structure of glaciers on their thermal radio emission. Atmospheric and Ocean Physics, 9(12), 1247-1256.

Mätzler, C. 1987. Applications of the interaction of microwaves with the natural snow cover. Remote Sensing Rev., 2(2), 259-387. 
Mosley-Thompson, E., J. Dai, L. G. Thompson, P.M. Grootes, J. K. Arbogast and J.F. Paskievitch. 1991. Glaciological studies at Siple Station (Antarctica): potential ice-core paleoclimatic record. F. Glaciol., 37(125), 11-22.

Palais, J. M., I. M. Whillans and C. Bull. 1982. Snow stratigraphic studies at Dome C, East Antarctica: an investigation of depositional and diagenetic processes. Ann. Glaciol., 3, 239-242.

Remy, F. and J. F. Minster. 1991. A comparison between active and passive microwave measurements of the Antarctic ice sheet and their association with the surface katabatic winds. F. Glaciol., 37(125), 3-10.

Ridley, J. K. and K. C. Partington. 1988. A model of satellite radar altimeter return from ice sheets. Int. $\mathcal{F}$. Remote Sensing, 9(4), 601-624.

Rotman, S. R., A.D. Fisher and D.H. Staelin. 1982. Inversion for physical characteristics of snow using passive radiometric observations. F. Glaciol., 28(98), 179-185.

Rott, H. 1989. Multispectral microwave signatures of the Antarctic ice sheet. In Pampaloni, P., ed. Microwave radiometry and remote sensing applications. Utrecht, VSP, 89-101.
Rott, H. and K. Sturm. 1991. Microwave signature measurements of Antarctic and Alpine snow. In Proceedings of the 11th EARSeL Symposium. Graz, Joanneum Research, 140-151.

Stiles, W. H. and F. T. Ulaby. 1982. Dielectric properties of snow. CRREL Spec. Rep. 82-18, 91-103.

Swift, C. T., P. S. Hayes, J. S. Herd, W. L. Jones and V.E. Delnore. 1985. Airborne microwave measurements of the southern Greenland ice sheet. 7. Geophys. Res., 90(B2), 1983-1994.

Tsang, L. and K. -H. Ding. 1991. Polarimetric signatures of a layer of random nonspherical discrete scatterers overlying a homogeneous half-space based on first- and second-order vector radiative transfer theory. IEEE Trans. Geosci. Remote Sensing, 29(2), 242-253.

Zhang, H., L. T. Pedersen and P. Gudmandsen. 1989. Microwave brightness temperatures of the Greenland ice sheet. Adv. Space Res., 9(1), 277-287.

Zwally, H.J. 1977. Microwave emissivity and accumulation rate of polar firn. F. Glaciol., 18(79), 195-215.

The accuracy of references in the text and in this list is the responsibility of the authors, to whom queries should be addressed. 